\title{
The use of role-play to enhance medical student understanding of genetic counseling
}

\author{
Dawn E. McIlvried, MS $S^{1}$, Sandra K. Prucka, $M S^{1}$, Matthew Herbst, $M S^{1}$, Christina Barger, $M S^{1}$,
} and Nathaniel H. Robin, $M D^{1,2}$

\begin{abstract}
Purpose: Advances in genetics have meant that genetic testing will become increasingly relevant to all health care fields. It is therefore important that all physicians have increased genetic education in their training, including in the medical school curriculum. Methods: To address this need, we used role-playing in an effort to enhance understanding of genetic counseling. Students were given the option of participating in a mock genetic counseling session whereby they would play the role of a patient receiving genetic test results. All students received questionnaires on their attitudes and knowledge about genetic counseling. Those who participated answered additional questions regarding effectiveness of the project. Results: Of 88 students who returned presimulation questionnaires, 19 opted to participate in the mock session, and 15 participants returned postsimulation questionnaires. There was no significant difference between participant and nonparticipant questionnaire responses. However, all participants agreed that role-play was effective in helping them understand genetic counseling and testing. Most participants also commented that the session helped them understand the importance of referral for genetic counseling and the impact of test results. Conclusions: The project proved overall valuable in improving medical student understanding of genetic counseling and may be applied to a variety of medical education settings to improve patient care. Genet Med 2008:10(10):739-744.
\end{abstract}

Key Words: role-play, medical school education, genetic counseling

Advances in human genetics have allowed for genetics services to become increasingly relevant in many areas of medicine. ${ }^{1-4}$ As genetic testing becomes more widely used in modern medical practice, all physicians will need to make appropriate health care recommendations to patients regarding genetic testing, and carry out genetic counseling. As has been shown previously, proper and adequate pre- and posttest genetic counseling is vital if patients are to receive the maximum benefit of such tests. ${ }^{5}$

Accordingly, there will be an increasing need for all health care providers to be familiar with the process of genetic testing and genetic counseling. However, outside of electives taken by a select few students, such training is absent from most medical school curricula and residency training programs. For this reason, most physicians will struggle to address genetic issues effectively with their patients. It is thus important to identify innovative educational opportunities within an already crowded

\footnotetext{
From the ${ }^{1}$ Departments of Genetics and ${ }^{2}$ Pediatrics, University of Alabama at Birmingham, Birmingham, Alabama.

Nathaniel H. Robin, MD, University of Alabama at Birmingham, Kaul 210, $15303 r d$ Ave So. Birmingham, AL 35243.E-mail: nrobin@uab.edu.

Disclosure: The authors declare no conflict of interest.

Submitted for publication April 28, 2008.

Accepted for publication July 18, 2008.

DOI: 10.1097/GIM.0b013e318187762e
}

medical curriculum to enhance clinical genetics education. One such technique is "role play."

Role-play is a training technique that is often used to develop student interaction and communication skills in a variety of disciplines and with learners of different backgrounds. ${ }^{6}$ It has been defined as "an experimental learning technique with learners acting out roles in case scenarios to provide targeted practice and feedback to train skills." 7 Role-play acknowledges the importance of the social context of learning and enables students to conceptualize their character and refine both professional and interpersonal roles in a simulated format. ${ }^{8}$ There are different methods of using role-play, whereby the student can play the role of the patient or of the caregiver, and this can involve interactions between two individuals or among larger groups. These methods can allow the student to take on an active role in a secure learning environment, without the potential limitations that can be inflicted by real-life situations and working with real patients.

Role-play has been shown to promote active learning, 9 which is valuable for student development of skills, knowledge, and attitude within therapeutic and educational settings. ${ }^{10}$ It also allows students to place themselves in scenarios that they had not previously experienced, where they can build upon empathetic abilities and better understand the motivations of others. ${ }^{9}$ By giving students the opportunity to experience these multiple perspectives, a greater awareness of the needs of both the health care provider and the client or patient can be at- 
tained. In turn, this can allow for more effective communication with patients and improved patient compliance including referral follow-through.

There is relatively little published regarding the effectiveness of using role-play as a medical student teaching tool, and to date there have been no reports of using role-play whereby the medical student assumes the role of the patient in a genetic testing scenario. We discuss here a project whereby medical students were given the opportunity to play the part of a patient receiving genetic test results and genetic counseling in a mock session. The aim of this study was to assess the effectiveness of using role-play in a medical education setting to enhance student understanding of the process and value of genetic counseling.

\section{METHODS}

During their course Genetics in Medicine, first year medical students (MS1) at the University of Alabama School of Medicine were invited to participate in a mock genetic counseling session. This invitation was made by an announcement before a lecture, during "Genetics in Medicine," an introductory class for MS1, and by a class-wide email. We chose MS1, as opposed to more advanced medical students or residents, because we felt that earlier exposure to the principles of genetic counseling would positively influence their later education. The study was explained to the students, and it was stated that they would play the role of a client receiving genetic test results. Participation was voluntary, and would not factor into their class grade. The study received approval by the University of Alabama at Birmingham (UAB) Institutional Review Board. Please refer Table 1 for the complete student study population demographics.

The mock counseling sessions took place in the clinical offices of the UAB Department of Genetics within a 2 month time span during the latter half of the semester. Participants in the mock sessions received by mail a brief clinical vignette that was randomly chosen from three different scenarios (vignettes are available on request): hereditary breast and ovarian cancer, fragile X syndrome, or autosomal recessive retinitis pigmentosa. We chose to use several different scenarios to allow the students to experience a wider variety of clinical situations.

Students were instructed to contact one of four genetic counselors and schedule a session to discuss their test results. The vignettes included background information on the respective condition each student was tested for, including its etiology, inheritance, associated health complications, management, and screening/surveillance recommendations, if applicable. There were also resources listed if the student wished to research the condition more thoroughly. The student was expected to read this information before receiving their test results. The results were assigned at random, with the exception of premutation versus full mutation for fragile X syndrome, which was dependant on the gender of the recipient. The range of possible test results included positive (affected), negative (unaffected), positive for carrier status but unaffected for autosomal recessive
Table 1

Medical student study population demographics

\begin{tabular}{|c|c|c|}
\hline & \multicolumn{2}{|c|}{ Sample distribution, \% $(N)$} \\
\hline & $\begin{array}{l}\text { Participants } \\
(N=19)\end{array}$ & $\begin{array}{l}\text { Nonparticipants } \\
\quad(N=69)\end{array}$ \\
\hline \multicolumn{3}{|l|}{ Gender } \\
\hline Male & $52.6(10)$ & $52.2(36)$ \\
\hline Female & $47.4(9)$ & $47.8(33)$ \\
\hline \multicolumn{3}{|l|}{ Ethnicity } \\
\hline Caucasian & $84.2(16)$ & $78.3(54)$ \\
\hline African-American & $15.8(3)$ & $7.2(5)$ \\
\hline Hispanic & 0 & 0 \\
\hline Asian & 0 & $14.5(10)$ \\
\hline Other & 0 & 0 \\
\hline \multicolumn{3}{|c|}{ Current education/degree level } \\
\hline College/Bachelor's & $78.9(15)$ & $88.4(61)$ \\
\hline Master's & $15.8(3)$ & $10.1(7)$ \\
\hline $\mathrm{PhD}$ & $5.3(1)$ & 0 \\
\hline Other & 0 & $1.4(1)$ \\
\hline \multicolumn{3}{|c|}{$\begin{array}{l}\text { Personal/family history of } \\
\text { genetic condition }\end{array}$} \\
\hline Yes & $26.3(5)$ & $15.9(11)$ \\
\hline No & $73.7(14)$ & $84.1(58)$ \\
\hline \multicolumn{3}{|c|}{$\begin{array}{l}\text { Previous experience with genetic } \\
\text { testing and/or genetic } \\
\text { counseling }\end{array}$} \\
\hline Yes & 0 & $4.3(3)$ \\
\hline No & $100(19)$ & $95.7(66)$ \\
\hline \multicolumn{3}{|c|}{$\begin{array}{l}\text { Previous training in patient } \\
\text { counseling }\end{array}$} \\
\hline Yes & $26.3(5)$ & $17.4(12)$ \\
\hline No & $73.7(14)$ & $82.6(57)$ \\
\hline
\end{tabular}

Data gathered from student questionnaires.

retinitis pigmentosa, and premutation for females with the fragile $\mathrm{X}$ vignette. We were especially interested in the issues brought up by a negative test/carrier status, as the psychosocial and counseling aspects surrounding this form of result have traditionally been less explored.

Before these sessions, a questionnaire was distributed to the entire class during the first week of GIM, to assess their attitudes and knowledge about genetic counseling (questionnaires are available on request). Students were asked to rate their understanding of genetic testing and genetic counseling, as well as their attitude on the role of nongenetics health care providers in the process of genetic testing and results disclosure. They were also asked open-ended questions about their motivations for participating and their expectations for the project as well as their anticipated responses regarding the test results. 
Table 2

Medical student questionnaire average values

\begin{tabular}{|c|c|c|c|c|}
\hline \multirow[b]{3}{*}{ Questions } & \multicolumn{4}{|c|}{ Average value $^{a}$} \\
\hline & \multicolumn{2}{|c|}{ Participants $(N=19)$} & \multicolumn{2}{|c|}{ Nonparticipants $(N=69)$} \\
\hline & Pre-sim & Post-sim & Pre-sim & Post-sim \\
\hline I have a good understanding of what is involved in the process of genetic testing & 2.5 & 4.5 & 2.7 & 4.1 \\
\hline I have a good understanding of what a genetic counselor does & 2.6 & 4.7 & 2.6 & 4.3 \\
\hline $\begin{array}{l}\text { I would feel comfortable giving genetic test results to a patient before making a } \\
\text { referral to a genetic professional }\end{array}$ & 2.3 & 3.1 & 2.5 & 2.8 \\
\hline $\begin{array}{l}\text { I feel that genetic counseling given by a genetic professional is necessary before } \\
\text { ordering genetic testing }\end{array}$ & 3.7 & 4.1 & 3.6 & 4.3 \\
\hline $\begin{array}{l}\text { I feel that a health care professional without formal genetics background or } \\
\text { training can effectively discuss genetic testing with a patient and order the } \\
\text { testing before making any referral to a genetic counselor }\end{array}$ & 2.8 & 2.3 & 2.5 & 2.2 \\
\hline $\begin{array}{l}\text { I feel that genetic test results can be effectively communicated to a patient over } \\
\text { the phone }\end{array}$ & 1.7 & 1.3 & 1.9 & 1.5 \\
\hline
\end{tabular}

${ }^{a}$ Values based on five-point rating score, where $1=$ strongly disagree, $2=$ disagree, $3=$ neutral/unsure, $4=$ agree, and $5=$ strongly agree.

After the simulation, students were given the same questionnaire to evaluate changes in their perception of genetics. However, questions were also included for participants to assess the effectiveness of the project in increasing student understanding of genetic counseling and testing, and what modifications the students felt should be made to improve the simulation.

\section{RESULTS}

\section{Presimulation questionnaires}

Of the 88 MS1 students who returned the presimulation questionnaires, 19 elected to participate in the mock genetic counseling sessions. The rate of participation was relatively low due to the fact it was a voluntary ungraded exercise. So, unless they were very motivated or there was a personal interest, students in that situation will not participate. Making this exercise mandatory would have increased participation, but because this was a pilot study we did not feel that would have been appropriate. Similarly, an incentive would have increased participation, but there were budgetary constraints.

The majority of students either disagreed or were neutral/ unsure that they had a good understanding of what is involved in the process of genetic testing (74\%) or that they had a good understanding of genetic counseling $(75 \%)$. Most students (67\%) disagreed or were neutral/unsure that they would feel comfortable giving genetic test results to a patient before referring them to a genetics professional, and $68 \%$ either agreed or were neutral/unsure that genetic counseling provided by a genetic professional was necessary before ordering genetic testing. Most students (74\%) were either neutral/unsure or disagreed that a health care professional without background or training in genetics can effectively discuss genetic testing with a patient before genetic testing. The majority of students (81\%) strongly disagreed or disagreed that genetic test results could be effectively communicated by phone. Overall, there did not seem to be a notable difference in responses between nonpar- ticipants and students who elected to participate in the project. Refer to Table 2 for questionnaire average response values for participants and nonparticipants before and after the simulation. See Table 3 for selected participant student comments regarding their expectations of the mock session before the simulation.

\section{Postsimulation questionnaires}

Of the 19 participants, 15 (79\%) and 17 nonparticipants returned the postsimulation questionnaires, giving a total of 32 responses. Most of the students (91\%) agreed or strongly agreed that they had a good understanding of what is involved in the process of genetic testing and that they had a good understanding of genetic counseling. Responses were divided among students as to whether they would be comfortable giving test results to a patient before referring them to a genetics professional. The majority of students (84\%) either agreed or strongly agreed that genetic counseling provided by a genetic professional was necessary before ordering genetic testing. Most students (75\%) disagreed or strongly disagreed that a health care professional without background or training in genetics can effectively discuss genetic testing with a patient before genetic testing. The majority of students (72\%) strongly disagreed that genetic test results could be effectively communicated by phone. Please refer to Figure 1 for a chart representation of the average response values given by medical students before and after the simulation.

There were no evident differences between participant and nonparticipant questionnaire responses. However, $100 \%$ of the participants agreed or strongly agreed that the role-play was effective in helping them to understand the process of genetic counseling and the implications of genetic testing. The majority of participants (12/15 or $80 \%$ ) agreed or strongly agreed that the exercise would benefit them in their ability to communicate with patients who might have a personal or fam- 
Table 3

Medical student postsimulation selected responses

Was your reaction to your test result what you anticipated it would be? If not, how was it different from what you expected?

"No, I actually expected a positive result. I guess I try to expect the worst and hope for the best. Also, I thought they might make everyone positive for a more informative learning experience."

"I anticipated it to be positive. I was a carrier and it felt strange because it was harder to think about what to discuss because it wasn't going to directly change my life but the siblings in the scenario."

"It was hard to really feel the feelings that the patient would have had because I didn't really feel like I had a problem."

"I can't answer the question very well because I wasn't really "role playing”-I'd never make it as an actress."

"The counselor did a good job of making the vignette feel real, and because of that, I had a stronger reaction than I expected."

"I was not really playing into my character, so I didn't have a big reaction. I was expecting the meeting to be more of a question and answer "what do genetic counselors do?" type of thing, instead of role-playing. That would have been fine, if I had been expecting it."

How was this exercise beneficial to you?

"I think I will be a much better resource to my patients by referring them to a genetic counselor."

"I learned about how basic the counselors have to get and that it must be difficult to fully explain the impact of results especially if (you are a) carrier."

"It helped me realize how overwhelmed a patient can be during the whole process."

"Allowed me a better understanding of what a genetic counselor does, and a chance to feel as a patient would feel (somewhat) while anticipating the results."

"It was very beneficial to see the actual process of how they sit you down, give you some background information, and discuss your results. I was surprised to see how fast they told you your results (meaning in the first few min of the visit). I think this is good because anyone coming in to discuss test results is focused completely on what the result is, and I think it's a good thing to go ahead and get it out there. The counselor immediately handed out some literature to read at home when everything sinks in, and at the moment she goes over pedigrees with you."

"I feel like I can better take care of patients that might have a genetic disease by understanding the importance of genetic counseling. It is important to see things from the patient's perspective too."

What would you change about this exercise?

"I think a vignette that goes over more issues would have a better choice. My vignette (RP + negative) didn't really touch on many issues other than that I was negative and possibly 'survivor's guilt.”"

"I think it would be even better to witness a real session. There's only so much we can pretend when it's us in the hot seat. There's no way to know how emotional genetic counseling is without seeing it."

"Explain that we get a range of results—maybe where carrier status affects life more (worse disease)."

"It was hard for me to role-play when I knew it wasn't true."

Please provide any other written feedback or comments.

"I thought it was interesting; I wish other health-related specialties would do the same to get a flavor for what they do (such as physical therapy, occupational therapy, etc.)"

"Good opportunity for future MD’s!"

"It was very helpful and beneficial and I think it's a great idea. Although knowing it's fake made it a bit awkward."

ily history of a genetic condition. All participants agreed or strongly agreed that the genetic counselor was effective in addressing the different issues of genetic testing and answering questions during the role-play. Please refer to Table 3 for selected participant student comments reflecting their attitudes on the effectiveness of the project postsimulation and suggestions for improvement.

\section{DISCUSSION}

To address a perceived deficiency in our medical school's curriculum, we developed an innovative educational program designed to enhance medical student's clinical genetics education using role-playing. Role-play is a training technique that is often used to develop student interaction and communications skills in a variety of disciplines and with learners of dif- ferent backgrounds. It acknowledges the importance of the social context of learning and enables students to conceptualize their character and refine both professional and interpersonal roles in a simulated environment. ${ }^{6,8}$ It has been shown to promote active learning, and it also places students in scenarios that they had not previously experienced, where they can build upon empathetic abilities and better understand the motivations of others in a secure learning environment, without the potential limitations that can be inflicted when working with real patients. ${ }^{7}$ Giving students the opportunity to experience different perspectives develops a greater awareness of the needs of both the health care provider and the client or patient. There is evidence that adequate physician-patient communication is related to better health outcomes, increased compliance and higher satisfaction of both the health care provider and the patient. ${ }^{11-13}$ 


\section{Medical Student Questionnaire Responses}

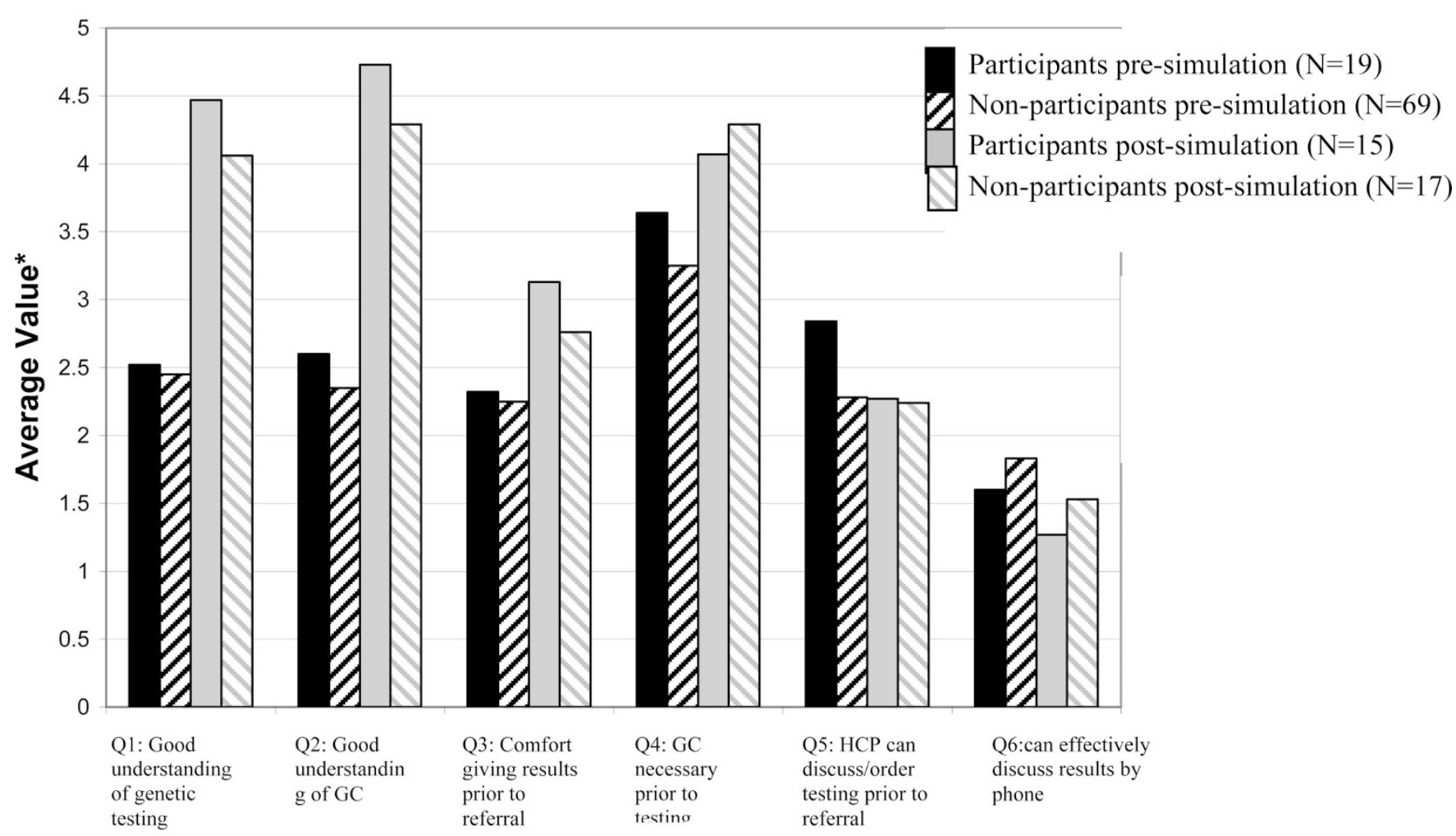

\section{Questions†}

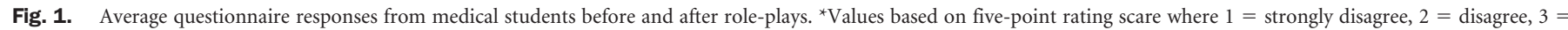

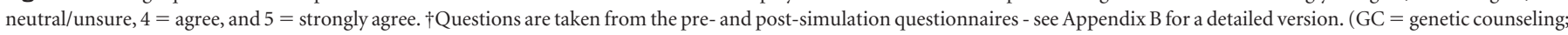
$\mathrm{HCP}=$ health care professional).

We found that, in general, there was essentially no evident difference between participant and nonparticipant questionnaire responses (Fig. 1). Of the students who returned questionnaires, the vast majority reported improvement in understanding the process of genetic counseling and genetic testing. This topic had been covered in several hours during the Genetics in Medicine course, implying that the didactic sessions were effective.

Although there was no evident difference in responses among participants and nonparticipants with regard to the questionnaires, all of the participants agreed or strongly agreed that role-play was effective in helping them understand the process of genetic counseling and the implications of genetic testing. The majority of participants also commented in written responses that the session helped them understand the importance of referral for genetic counseling and the impact of test results both emotionally and with regard to patient health care. This indicates that the mock sessions were helpful in a different manner than the lectures alone in increasing student understanding of the genetic counseling and testing process.

Some students commented that the role-play was difficult for them because it was conducted in a simulated environment and required some amount of acting, which felt unnatural or awkward. Some felt as though they did not gain full empathetic benefit of the mock session by knowing that "it wasn't true." Such limitations of role-playing have been mentioned in other studies, ${ }^{8,14}$ and it should be recognized that this type of teaching method is a single part of a more comprehensive learning and communication process. Role-play is a method that usually works best in preplanned and structured situations that are kept as realistic as possible, with motivated students who are willing to actively engage in the simulation, and with feedback and discussion regarding the experience. ${ }^{714-16}$

A few students also mentioned that if they had a negative or normal test result, or if they were an asymptomatic carrier, they felt as though this type of scenario was not as educational and that there was not as much to discuss during the session as there would have been with a positive test result. However, it is important to also note that, regardless of the test result, the students (acting as patients) do have a close family member affected with the condition, and it was therefore still of value to discuss the condition at length and its emotional implications and impact on health care. Also, for those who were carriers for a recessive condition or positive for a premutation, the test results did have impact on reproductive or prenatal diagnostic options, and significance for any offspring. Finally, as noted by 
one student, even negative test results can carry an emotional burden such as survivor's guilt.

One obvious limitation of this study is the small sample size, especially in the number of returned responses. But although the number of participants was small, the feedback does provide valuable insight. Although it would be desirable to expand the program to include a larger number of students, it is a difficult proposition given the amount of time required for the genetic counselors. UAB has a small cohort of four genetic counselors. To increase the number of students would require lengthening the time of the program to the entire first year, and potentially include other genetics professionals and trainees, such as genetic counseling students. Most medical schools, however, do not have a genetics program that can commit such resources to MS1 education. In addition, we did not perform any formal statistical calculations on the data provided. Part of the reasoning behind this is because the sample size is small, which would make it difficult to draw any conclusions, and because the value and aim of this project can be inferred from the raw information that was obtained, most particularly from participant written responses.

\section{CONCLUSION}

Although it seems that role-playing alone did not influence student perceptions about genetic counseling, it is evident via student written comments that the project proved overall valuable in improving medical student understanding and appreciation of genetic counseling. These mock sessions provided medical students an opportunity to experience the complexity of the genetic testing process and communication of these re- sults. Although this project design and concept are not particularly complex, it does require a significant commitment from a genetics center, and such resources may not be available at every medical school.

\section{References}

1. Acheson LS, Wiesner GL. Current and future applications of genetics in primary care medicine. Prim Care 2004;31:449-460.

2. Emery J, Hayflick S. The challenge of integrating genetic medicine into primary care. BMJ 2001;322:1027-1030.

3. Korf BR. Integration of genetics into clinical teaching in medical school education. Genet Med 2002;4:S33-S38.

4. Taylor MR, Edwards JG, Ku L. Lost in translation: challenges in the expanding field of adult genetics. Am J Med Genet 2006;142C:294-303.

5. Brunger JW, Murray GS, O’Riordan MA, Matthews AL, Smith RHJ, Robin NH. Parental attitudes toward genetic testing for pediatric deafness. Am J Hum Genet 2000;67:1621-1625.

6. Nikendei C, Zeuch A, Dieckmann P, et al. Role-playing for more realistic technical skills training. Med Teach 2005;27:122-126.

7. Kiger AM. Teaching for health. Edinburgh: Churchill Livingstone, 2004.

8. Joyner B, Young L. Teaching medical students using role-play: twelve tips for successful role-plays. Med Teach 2006;28:225-229.

9. van Ments M. The effective use of role-play. London: Kogan Press, 1999.

10. Bell M. Online role play: anonymity, engagement and risk, 2001. Available at: http:// www.tandf.co.uk/journals. Accessed August 1, 2007.

11. Benbassat J, Baumal R. A step-wise role playing approach for teaching patient counseling skills to medical students. Patient Educ Couns 2002;46:147-152.

12. Stewart MA, Brown JB, Weston WW, McWhinney IR, McWilliam CL, Freeman TR. Patient-centered medicine: transforming the clinical method (patient-centered case series). Thousand Oakes, CA: Sage Publication, 1995.

13. Windish DM, Price EG, Clever SL, Magaziner JL, Thomas PA. Teaching medical students the important connection between communications and clinical reasoning. J Gen Int Med 2005;20:1108-1113.

14. Nestel D, Tierney T. Role-play for medical students learning about communication: guidelines for maximizing benefits. BMC Med Educ 2007;7:3.

15. Kneebone R. Evaluating clinical simulations for learning procedural skills: a theorybased approach. Acad Med 2005;80:549-553.

16. Shearer R, Davidhizar R. Using role play to develop cultural competence. J Nurs Educ 2003;42:273-276. 